\title{
A wood density and aboveground biomass variability assessment using pre-felling inventory data in Costa Rica
}

\author{
Sienna Svob, J Pablo Arroyo-Mora* and Margaret Kalacska
}

\begin{abstract}
Background: The high spatio-temporal variability of aboveground biomass (AGB) in tropical forests is a large source of uncertainty in forest carbon stock estimation. Due to their spatial distribution and sampling intensity, pre-felling inventories are a potential source of ground level data that could help reduce this uncertainty at larger spatial scales. Further, exploring the factors known to influence tropical forest biomass, such as wood density and large tree density, will improve our knowledge of biomass distribution across tropical regions. Here, we evaluate (1) the variability of wood density and (2) the variability of AGB across five ecosystems of Costa Rica.
\end{abstract}

Results: Using forest management (pre-felling) inventories we found that, of the regions studied, Huetar Norte had the highest mean wood density of trees with a diameter at breast height (DBH) greater than or equal to $30 \mathrm{~cm}$, $0.623 \pm 0.182 \mathrm{~g} \mathrm{~cm}^{-3}$ (mean \pm standard deviation). Although the greatest wood density was observed in Huetar Norte, the highest mean estimated AGB (EAGB) of trees with a DBH greater than or equal to $30 \mathrm{~cm}$ was observed in Osa peninsula $\left(173.47 \pm 60.23 \mathrm{Mg} \mathrm{ha}^{-1}\right)$. The density of large trees explained approximately $50 \%$ of EAGB variability across the five ecosystems studied. Comparing our study's EAGB to published estimates reveals that, in the regions of Costa Rica where AGB has been previously sampled, our forest management data produced similar values.

Conclusions: This study presents the most spatially rich analysis of ground level AGB data in Costa Rica to date. Using forest management data, we found that EAGB within and among five Costa Rican ecosystems is highly variable. Combining commercial logging inventories with ecological plots will provide a more representative ground level dataset for the calibration of the models and remotely sensed data used to EAGB at regional and national scales. Additionally, because the non-protected areas of the tropics offer the greatest opportunity to reduce rates of deforestation and forest degradation, logging inventories offer a promising source of data to support mechanisms such as the United Nations REDD + (Reducing Emissions from Tropical Deforestation and Degradation) program.

Keywords: Forest management; Aboveground biomass; Wood density; Tropical forest; Costa Rica

\section{Introduction}

Tropical forests play a vital role in regulating the Earth's climate through the processes of evapotranspiration and $\mathrm{CO}_{2}$ uptake. While these areas represent only $7 \%$ of global land cover [1], they store roughly $55 \%$ of the world's forest carbon stock [2]. Tropical forests are among the most carbon dense ecosystems $\left(242 \mathrm{Mg} \mathrm{C} \mathrm{ha}^{-1}\right)$ in the

* Correspondence: pablo.arroyo@mcgill.ca

Department of Geography, McGill University, Burnside Hall Building, H3A OB9 Montreal, QC, Canada world [2]. Approximately 56\% (193-223 Pg C) of their carbon is stored in the form of biomass alone [2-4]. During the 1990s and early 2000s, a substantial portion of this carbon stock suffered due to deforestation, which reached an estimated rate of $12.9 \cdot 10^{6}{\text { ha } \mathrm{yr}^{-1}}_{\text {[5]. The }}$ deforestation and degradation of tropical forests is also the second largest source of anthropogenic $\mathrm{CO}_{2}$ emissions [6], releasing carbon at an estimated net rate of 1.0 Pg $\mathrm{yr}^{-1}$ between 2000 and 2010 [4].

The United Nations REDD + (Reducing Emissions from Deforestation and Forest Degradation) program is

\section{国}


an innovative global mechanism that aims to provide monetary benefits to developing tropical countries that can show an increase in forest carbon stocks from an established national baseline [7]. In the past decade, the number of studies seeking to improve the methods and data used to accurately estimate the spatio-temporal variation of tropical forest carbon stocks, supporting REDD+, have substantially increased [8]. Today, much of this research relies upon the relationship between aboveground biomass (AGB) and forest carbon. Despite recent efforts to estimate $A G B$ in the tropics (and in turn carbon) (refer to $[3,4,9]$ ), a large degree of uncertainty in the spatial distribution and accuracy of these estimates remains $[10,11]$. One of the key factors in reducing uncertainty in AGB estimates is using a spatial scale fine enough to capture variability across the landscape.

Remote sensing and ground data (i.e. forest inventories) are two techniques that have been proposed for the production of reliable carbon estimates (e.g. [12]). Remote sensing is an advantageous approach as it can provide wall-to- wall coverage of an entire country. Remotely sensed data, however, must be calibrated/validated with ground truth measurements [13,14]. Additionally, remote sensing instruments may not be sensitive enough to detect the variability of biomass within and across the high-density forest stands $[14,15]$ typical of tropical moist and tropical wet ecosystems. Ground data collected for scientific research (ecological data), is the most common data source employed to estimate AGB due to its high level of detail and systematic nature. Nevertheless, ecological data has its own weaknesses when estimating AGB such as: (1) the standard plot size of 0.1 ha [16] is too small to capture AGB variability [17]; (2) plots are sometimes biased towards high density (ideal) forest locations [16]; and (3) plots cover only a small fraction of a country's total forested area [18]. Commercial logging inventories may provide a solution to these problems due to their spatial distribution and sampling intensity $[18,19]$. Logging inventories are common to tropical countries and represent a large source of data on forest structure and composition [20]. With their success in measuring diversity on large spatial scales [21], determining ecological factors that influence forest structure [19], and estimating emission factors under REDD + [18], logging inventories may provide a suitable source of forest data, complementing ecological datasets and helping to estimate baseline carbon stocks.

In Costa Rica, selective logging inventories or prefelling inventories (we use this terminology in the paper indistinctively) are developed under a Natural Forest Management Plan (NFMP) framework [22]. NFMP data is available for most of the country's ecosystems below an elevation of 300 meters, accurately representing the heterogeneity of the Costa Rica's lowland landscape. The country is divided into 11 conservation areas (CAs) [23], each encompassing distinct forest ecosystems. Despite the country's small size (approximately $51000 \mathrm{~km} 2$ ), it contains a rich diversity of tropical ecosystems ranging from dry to wet forests.

A NFMP is required before the forest stand of a privately owned property can be selectively logged. In order to be legally approved to log, the owner must hire a certified forester to conduct an inventory and census of the forest stand [22]. In an inventory, every tree with a diameter at breast height (DBH) equal to or greater than $30 \mathrm{~cm}$ is measured and identified in plots of 0.3 ha. For the same forest stand, a census is carried out to measure and identify every tree with a DBH equal to or greater than $60 \mathrm{~cm}$. For this study we use a standardized relational geodatabase encompassing Costa Rican pre-felling inventory data [24].

The main objective of this study is to assess to variability of wood density and estimated AGB across five ecosystems in Costa Rica. Wood density is an important predictive variable when estimating AGB [16,25-27]. As wood density is known to vary among different forest communities [28-31], this variable is also critical to studying the differences in AGB across a landscape. Despite these findings, wood density has yet to be studied or implemented when estimating AGB across Costa Rica. Further, although our analysis is based on medium to large trees (30 and $60 \mathrm{~cm} \mathrm{DBH),} \mathrm{studies} \mathrm{have} \mathrm{shown} \mathrm{that}$ large trees constitute a disproportionate fraction of AGB and drive the variations in biomass across the tropics [32]. Therefore, despite a lack of tree data below the $30 \mathrm{~cm}$ DBH range, patterns of AGB variability may be discernible from our NFMP dataset. A standard method to estimate a tree's biomass employs an allometric equation to relate measurements on DBH to units of biomass. The choice of allometric model is critical and should be based upon both the aim of the study [28] and the characteristics of the dataset [33]. Allometric models should be representative of the $\mathrm{DBH}$ range and ecosystem being studied [33]. Additionally, to allow for regional scale comparisons, AGB estimates must be based on a consistent regression approach to avoid the confounding of results by variations inherent in different models [28].

In recent years, the pantropical allometric models developed by Chave et al. [25] have been widely applied across the globe to estimate AGB. In Costa Rica, however, numerous studies of biomass have employed Brown's [34] equation for wet forests (e.g. $[17,35,36]$ ) as it was calibrated with data collected at Costa Rica's La Selva Biological Station. For this study, we believe Brown's [34] equation has many disadvantages when compared to those developed by Chave et al. [25]. These shortcomings include: (1) the representation of a smaller DBH range; (2) the development of the equation from a smaller sample size; (3) the limited application of the 
equation outside of Costa Rica (making the comparison of AGB estimates with other countries/studies more complex); and (4) the absence of wood density as a parameter which is an aspect of forest structure that varies significantly at regional scales $[28,30]$.

With the use of allometric models [25], the Global Wood Density database [30,37], the pre-felling inventory database [24], and national measurements of wood density found in the scientific literature (e.g. [38]), this study will first, evaluate the variability in wood density and second, assess the variability in estimated AGB across five ecosystems in Costa Rica and different sampling protocols. Specifically, our study uses a NFMP database for five conservation areas to address the following questions:

(1) What are the patterns of wood density variability at the CA-level and between data produced by the census and inventory (i.e. sampling protocols)?;

(2) What is the variability of estimated AGB within and among CAs?;

(3)Do estimated AGB values differ between the two sampling protocols?

(4)What is the uncertainty associated with AGB estimated using natural forest management data?

As ground level data from pre- felling inventories covers a greater area than ecological plots within the five ecosystems being studied, our study will better capture the spatial heterogeneity of wood density and estimated AGB across the landscape. Through this analysis, we can enhance our understanding of the spatial distribution of estimated AGB and, in combination with both ecological and remotely sensed data, more reliably map and estimate national forest carbon stocks.

\section{Methods}

\section{Study area and data}

This study used a database of NFMPs from five conservation areas: ACLA-C (Caribbean La Amistad Conservation Area), ACAHN (Arenal Huetar Norte Conservation Area), ACTO (Tortuguero Conservation Area), ACCVC (Central Volcanic Conservation Area), and ACOSA (Osa Conservation Area) (Figure 1). Greater detail about the NFMP database and the taxonomic, wood density, spatial, and tree measurement data used in this study is provided in Svob et al. [24]. The differences found between the historical patterns of natural forest management of the five conservation areas, such as the number of NFMPs per conservation area, forest fragmentation statistics specific to each conservation area, and descriptive statistics based on the NFMPs collected in each conservation area, are given in Arroyo-Mora et al. [39]. The five conservation areas considered in this study cover the country's Atlantic lowland forests, northern lowlands, and central and south Pacific forests, encompassing the regions where selective logging has been most heavily practiced. All five conservation areas include natural forest management plans that fall within the tropical wet (4000$8000 \mathrm{~mm}$ precipitation $\left.\mathrm{yr}^{-1}\right)$ and/or rain $(>8000 \mathrm{~mm}$ precipitation $\mathrm{yr}^{-1}$ ) forest lifezones (defined by Holdridge [40]). Only ACLA-C and ACAHN include natural forest management plans that represent the tropical moist (2000-4000 $\mathrm{mm}$ precipitation $\mathrm{yr}^{-1}$ ) forest lifezone. The management plans sampled largely represent a lowland ecosystem (0-500 $\mathrm{m}$ a.s.l.) although a small subset of the data falls within the transition zone from lowland to premontane (500-1500 m a.s.l.) forest. The forest type of the natural forest management plans was classified using the Life Zone System Map from the Atlas Costa Rica 2008 [41]. All management plans were carried out in primary forest (old growth).

\section{The variability of wood specific gravity among CAs and sampling protocols}

The variability of wood density across Costa Rica can be illustrated by differences found in wood density between conservation areas, NFMPs, and the different sampling protocols (census and inventory). The greater the variability in wood density, the more important it becomes to include this parameter when producing AGB estimates comparable at a landscape-scale. To carry out the analysis, we excluded data from NFMPs with less than $80 \%$ of their trees identified to the species or genus level. The wood density value for each tree in a NFMP was selected in decreasing order of preference from (1) a species-level average, (2) a genus-level average, and (3) a NFMP-level average. Mean NFMP wood density was calculated separately for each census and inventory. Wood density values were extracted from the NFMP database and are described in greater detail in Svob et al. [24]. These NFMP averages were determined by summing the wood density of all stems with a species or genus level value. Differences between the wood density of the conservation areas and the two different sampling protocols were tested with a one-way ANOVA and a multiple comparisons procedure using the grouping variables conservation area and sampling protocol. All conservation area level statistical analyses only included tree data that met the aforementioned NFMP taxonomic identification conditions. All of the analyses were carried out in MATLAB version R2013b (The MathWorks Inc., Natick, MA, USA) unless otherwise specified.

\section{Estimating tree-level AGB}

In this study, we denote estimated $A G B$ as estimated aboveground biomass (EAGB), following Clark and Kellner [10]. To determine EAGB per tree, Chave et al.'s [25] allometric models for wet and moist forests were applied. The 


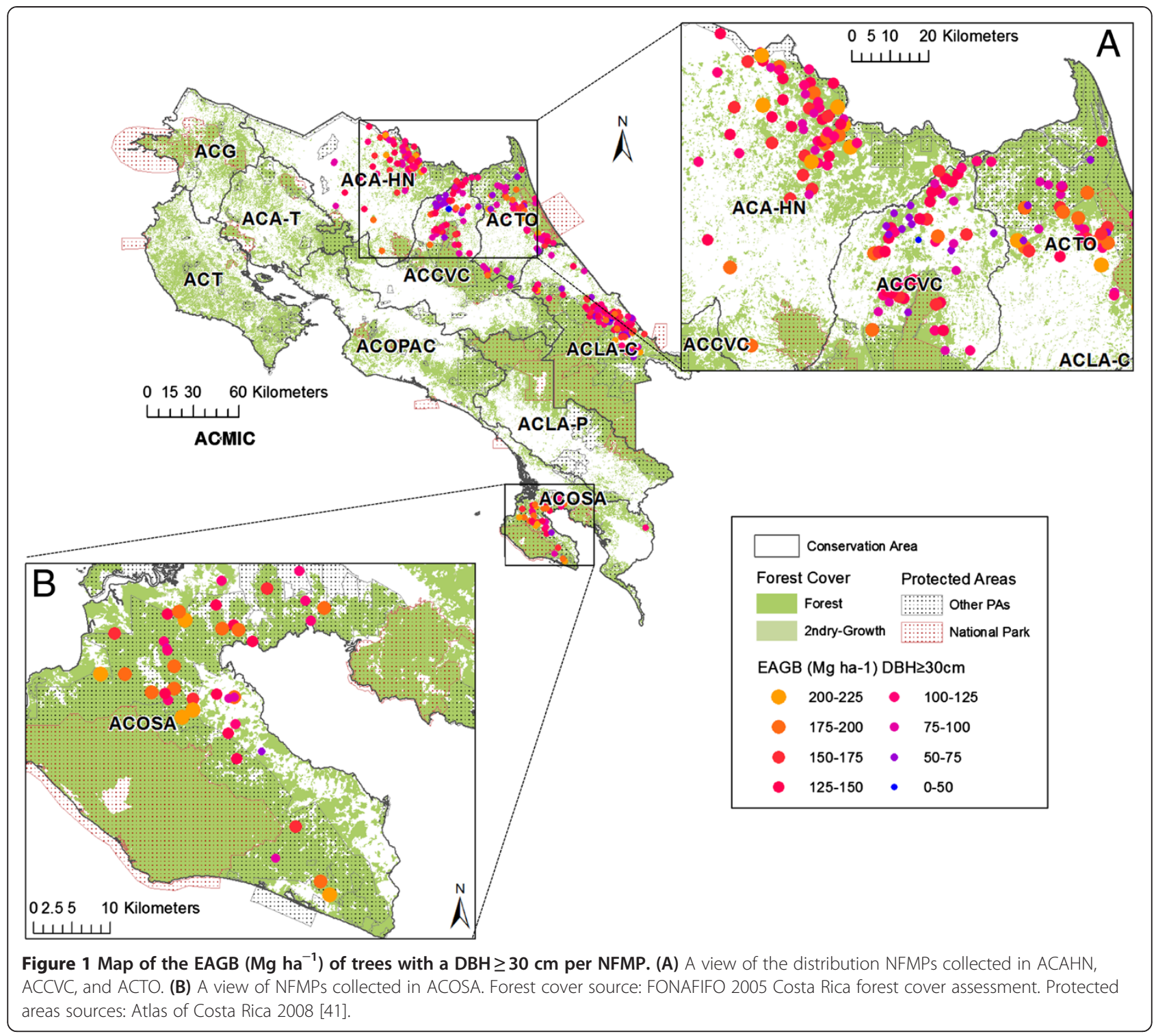

EAGB of wet and rain forest lifezones was estimated by applying the wet forest equation:

$$
\begin{aligned}
E A G B= & \rho \times \exp (-1.239+1.980 \times \ln (\mathrm{DBH})+0.207 \\
& \times \ln (D B H)^{2}-0.0281 \times \ln (D B H)^{3}
\end{aligned}
$$

Correspondingly, the EAGB of forests within the tropical moist lifezones was estimated using the moist forest equation:

$$
\begin{aligned}
E A G B= & \rho \times \exp (-1.499+2.148 \times \ln (\mathrm{DBH})+0.207 \\
& \times \ln (D B H)^{2}-0.0281 \times \ln (D B H)^{3}
\end{aligned}
$$

where $\rho$ is wood density in $\mathrm{g} \mathrm{cm}^{-3}, \mathrm{DBH}$ is in $\mathrm{cm}$, and EAGB is given in $\mathrm{kg}$ tree ${ }^{-1}$. Wood density values were selected in decreasing order of preference from (1) a species-level average, (2) a genus-level average, (3) a NFMP-level average, and (4) a conservation area level average. A large portion of the variation in wood density is captured at the genus-level, making mean genus wood density the second best option when estimating EAGB $[28,30]$. We use the mean NFMP wood density for a tree that was present in a NFMP with at least $80 \%$ of its trees identified to the genus or species level and was missing a corresponding species or genus level wood density. For a tree that was reported in a NFMP with less than $80 \%$ of its trees identified to the species or genus level and lacked wood density information, we used a conservation area level mean wood density.

\section{Estimating census and inventory AGB}

To calculate EAGB per unit area of a census, the EAGB values per tree with a $\mathrm{DBH}$ greater than or equal to 
$60 \mathrm{~cm}$ were summed and then divided by the productive area of the NFMP's forest stand. The productive area is the total area of the forest stand sampled by a census. To calculate EAGB per unit area of an inventory, the EAGB values per tree with a $\mathrm{DBH}$ greater than or equal to $30 \mathrm{~cm}$ were summed across each plot and then divided by 0.3 ha (area of the plot). Finally, EAGB was averaged across all plots within a given NFMP.

An outlier analysis of all of the resulting EAGB values was performed, pinpointing cases where EAGB did not fall between the 1.5 lower and 1.5 upper interquartile range. All outliers were cross-checked with the original hardcopy versions of the NFMPs. If the values were the result of uncorrectable errors present in the original NFMPs, they were excluded from any further analyses. To assess the amount of spatial autocorrelation among the NFMPs sampled, we evaluated the distribution of Moran's I with a spatial correlogram as applied in SAM version 4.0. Spatial correlograms indicate the correlation between pairs of spatial observations as the distance between them is increased [42]. As the values of Moran's I were relatively small, ranging between 0.154 and -0.209 , we did not include any additional methodological approaches to account for spatial autocorrelation in later analyses.

\section{Comparing the EAGB of the sampling protocols and CAs}

Differences in EAGB between conservation areas and between sampling protocols (tree census vs tree inventory) were tested with a one-way ANOVA and a multiple comparisons procedure using conservation area and sampling protocol as the grouping variables. We also evaluated differences in the density of large trees $(\mathrm{DBH} \geq$ $70 \mathrm{~cm}$ ) between CAs and sampling protocols, as the recent study of Slik et al. [32] found that large trees explained up to $70 \%$ of the variation in EAGB across the tropics.

In order to compare the data captured by inventories and censuses more directly, EAGB was recalculated for each inventory including only the trees that would be sampled during a census $(\mathrm{DBH} \geq 60 \mathrm{~cm})$. To assess whether there was a significant difference in this data, a paired $t$-test was applied. As multiple NFMPs only included census data (DBH $\geq 60 \mathrm{~cm}$ ), we attempted to develop a model to estimate the EAGB of stems with a $\mathrm{DBH} \geq 30 \mathrm{~cm}$ and a DBH $<60 \mathrm{~cm}$. We attempted to develop a model by relating, for each pre-felling inventory, the EAGB of trees with a DBH $\geq 60 \mathrm{~cm}$ to the EAGB of trees with a $\mathrm{DBH} \geq 30 \mathrm{~cm}$ and a $\mathrm{DBH}<60 \mathrm{~cm}$. We compared the ability of a number of regression models (linear, exponential, logistic, and polynomial) to capture a relationship between EAGB $(\mathrm{DBH} \geq 60 \mathrm{~cm})$ and EAGB $(60 \mathrm{~cm}<\mathrm{DBH} \leq 30 \mathrm{~cm})$.

\section{Evaluating the uncertainty of AGB estimates}

Uncertainty can be introduced to a tree's EAGB through DBH measurement errors $(\sigma \mathrm{MDBH})$, wood density measurement errors $(\sigma \mathrm{M} \rho)$, and errors inherent in the allometric model itself $(\sigma \mathrm{A})$ [33]. In this study, we evaluated the uncertainty of tree-level AGB estimates introduced by error in wood density measurements $(\sigma \mathrm{M} \rho)$ at the four following levels: species ( $\sigma \mathrm{M} \rho: \mathrm{sp})$, genus ( $\sigma \mathrm{M} \rho$ : gen), NFMP ( $\sigma \mathrm{M} \rho$ :NFMP), and conservation area ( $\sigma \mathrm{M} \rho$ : $\mathrm{CA})$. We hypothesized that the measurement error will increase as the source of wood density increases in taxonomic scale. To evaluate errors introduced by the allometric models themselves, we reiterated the calculation of a tree's EAGB while varying $\varepsilon$ (Equations 3 and 4 ) based on the residual standard error (RSE). Monte Carlo simulations were run in MATLAB version R2013b (The MathWorks Inc., Natick, MA, USA) to simulate the parameters (wood density and residual standard error of the allometric model $(\varepsilon)$ ) and determine both wood density measurement error and allometric model error.

As wood density values vary at the tree level within NFMPs, conservation areas, species, and genera [30], using mean wood density values to estimate AGB will introduce measurement error. Further, in forest management inventories, trees are identified in the field by common names and later related to scientific names. This methodology can result in the misidentification of species [43] and therefore, additional wood density measurement errors. We evaluate wood density errors under the assumption that the errors have a centered normal distribution. The distribution of errors for each tree uses the calculated mean and standard deviation of the appropriate species, genus, NFMP, or conservation area. We randomly selected 10000 trees (5000 from the census and 5000 from the inventory) to evaluate the uncertainty at each level. For each tree, we calculated EAGB 1000 times while varying the wood density parameter by a random normal distribution.

As allometric models are typically created using a regression on log-transformed variables, there is inherent error built in them. This uncertainty is the result of trees departing from the exact allometry described by the models [33]. Errors in tree AGB estimates due to the allometric model were assessed by varying $\varepsilon$ (Equation 3 and 4) following the methodology of Maniatis et al. [18]. We assumed that $\varepsilon$ followed a centered normal distribution with a mean of 0 and a standard deviation of 0.356 (residual standard error reported for the models in Chave et al. [25]). $\varepsilon$ was incorporated into the EAGB equations using the same structure as Maniatis et al. [18]. For wet forests the model became:

$$
\begin{aligned}
E A G B= & \rho \times \exp (-1.302+1.980 \times \ln (D B H)+0.207 \\
& \left.\times \ln (D B H)^{2}-0.0281 \times \ln (\mathrm{DBH})^{3}\right) \times \exp (\varepsilon)
\end{aligned}
$$


while for moist forests is became:

$$
\begin{aligned}
E A G B= & \rho \times \exp (-1.562+2.148 \times \ln (D B H)+0.207 \\
& \left.\times \ln (D B H)^{2}-0.0281 \times \ln (\mathrm{DBH})^{3}\right) \times \exp (\varepsilon)
\end{aligned}
$$

Following the previously described methodology, 10 000 were randomly selected from the census and inventory and, for each tree, EAGB was calculated 1000 times while varying the $\varepsilon$ parameter by a random normal distribution

To evaluate the uncertainty of EAGB at the census and inventory levels, EAGB was simulated 1000 times for every tree of 100 randomly selected censuses and 100 randomly selected inventories. For each simulation, we varied both wood density and $\varepsilon$ simultaneously following the above sampling methodology. Simulated EAGB values were compared, revealing the uncertainty and precision of the reported EAGB values.

\section{Results}

\section{The variability of wood density}

Among all conservation areas, ACLA-C had a significantly lower wood density (inventory: $0.528 \pm 0.161 \mathrm{~g} \mathrm{~cm}^{-3}, \mathrm{p}<$ 0.01 ; census: $0.530 \pm 0.1520 \mathrm{~g} \mathrm{~cm}^{-3}, \mathrm{p}<0.01$ ) (mean \pm standard deviation unless otherwise specified) (Table 1). No difference in wood density was detected in the census data among ACOSA, ACCVC, and ACAHN. Based on the inventory data set (either $\mathrm{DBH} \geq 30 \mathrm{~cm}$ or only including $\mathrm{DBH} \geq 60 \mathrm{~cm}$ ), however, ACAHN had a significantly higher wood density than the other four conservation areas $\left(0.623 \pm 0.182 \mathrm{~g} \mathrm{~cm}^{-3}\right.$ and $0.636 \pm 0.197 \mathrm{~g} \mathrm{~cm}^{-3}$ respectively). The greater mean wood density found in ACAHN is due to a larger fraction of trees within the 0.8 to $0.9 \mathrm{~g} \mathrm{~cm}^{-3}$ range (Figures 2A and 2B). This is a result of the high density of the Dialium guianensis in ACAHN [24]. In ACCVC and ACTO, a prominent peak in the percent of stems within the 0.6 to $0.7 \mathrm{~g} \mathrm{~cm}^{-3}$ range can be attributed to the high relative frequency of Pentaclethra macroloba. The range of wood density values sampled was

Table 1 Wood density $\left(\mathrm{g} \mathrm{cm}^{-3}\right)$ per conservation area and sampling protocol

\begin{tabular}{llll}
\hline & \multicolumn{3}{l}{ Wood Density $\left(\mathbf{g ~ c m}^{\mathbf{3}}\right)$} \\
\cline { 2 - 4 } & \multicolumn{3}{l}{ (Mean \pm Std) } \\
\cline { 2 - 4 } CA & $\begin{array}{l}\text { Inventory } \\
(\mathbf{D B H} \geq \mathbf{3 0} \mathbf{~ c m})\end{array}$ & $\begin{array}{l}\text { Inventory } \\
(\mathbf{D B H} \geq \mathbf{6 0} \mathbf{~ c m})\end{array}$ & $\begin{array}{l}\text { Census } \\
\mathbf{( D B H} \geq \mathbf{6 0} \mathbf{~ c m})\end{array}$ \\
\hline ACAHN & $0.623 \pm 0.182$ & $0.636 \pm 0.197$ & $0.602 \pm 0.189$ \\
ACCVC & $0.602 \pm 0.144$ & $0.579 \pm 0.170$ & $0.600 \pm 0.143$ \\
ACLA-C & $0.528 \pm 0.161$ & $0.579 \pm 0.171$ & $0.530 \pm 0.152$ \\
ACOSA & $0.574 \pm 0.165$ & $0.579 \pm 0.169$ & $0.604 \pm 0.166$ \\
ACTO & $0.565 \pm 0.143$ & $0.578 \pm 0.169$ & $0.564 \pm 0.140$ \\
\hline
\end{tabular}

similar in all five conservation areas. Additionally, in all conservation areas, the mean wood density sampled by the inventory and that sampled by the census did not significantly differ.

\section{The variability of EAGB}

Based on inventory data, the estimated AGB (EAGB) $(\mathrm{DBH} \geq 30 \mathrm{~cm})$ found in ACAHN and ACCVC was significantly lower than that in ACLA-C and ACOSA ( $<<$ 0.05) (Figure 3 and Table 2). While ACAHN, ACCVC, ACTO, and ACLA-C all shared similar inventory EAGB values with at least one other conservation area, only in ACOSA did EAGB differ significantly from all other CAs. In fact, ACOSA presented the highest mean inventory EAGB $\left(173.47 \pm 60.23 \mathrm{Mg} \mathrm{ha}^{-1}, \mathrm{p}<0.05\right)$.

Based on census data, ACAHN had the lowest EAGB, significantly differing from ACLA-C, ACTO, and ACOSA $(\mathrm{p}<0.05)$ (Figure 4 and Table 2). Simply ranking conservation areas in decreasing order of mean EAGB (Table 2), reveals that the overall trends are similar between sampling protocols. For example, ACAHN had one of the lowest mean EAGB values in both the census and inventory data $\left(39.77 \pm 23.48 \mathrm{Mg} \mathrm{ha}^{-1}\right.$ and $\left.136.63 \pm 60.08 \mathrm{Mg} \mathrm{ha}^{-1}\right)$. A paired $t$-test comparing the EAGB of trees with a $\mathrm{DBH} \geq 60 \mathrm{~cm}$ from the census and inventory detected a significant difference between the two sampling protocols $(\mathrm{n}=366, \mathrm{p}<0.01)$. Across all five conservation areas, inventories generally produced higher EAGB values than censuses of the same forest stand (Figure 5).

Our attempt to relate the EAGB of trees with a $\mathrm{DBH} \geq$ $60 \mathrm{~cm}$ to the EAGB of trees with a DBH $\geq 30 \mathrm{~cm}$ but $<60 \mathrm{~cm}$ did not indicate a strong relationship between the two variables (e.g. linear regression results adj $R^{2}$ : $0.043, \mathrm{~F}=19.9, \mathrm{p}<0.01, \mathrm{n}=422$ ). Although we were unable to find a relationship between the two variables, this analysis demonstrates the amount of variance in the structure of Costa Rican forests (Figure 6A).

\section{The density of large trees (DBH $\geq 70 \mathrm{~cm}$ )}

We found a significant correlation between the densities of large trees $(\mathrm{DBH} \geq 70 \mathrm{~cm})$ and EAGB $(\mathrm{DBH} \geq 30 \mathrm{~cm})$ (correlation coefficient: $0.728, \mathrm{n}: 422$, adj $\mathrm{R}^{2}: 0.533, \mathrm{~F}=$ 470.6, p < 0.01) (Figure 6B). Our results show that 53.3\% of the variation in EAGB across five Costa Rican conservation areas was explained by the density of large trees. Additionally, trends in the density of large trees per conservation area match trends in EAGB per conservation area. For example, in ACOSA, the EAGB and density of large trees $\left(16.48 \pm 8.08\right.$ tree ha $\left.^{-1}\right)$ were both significantly higher than in the four other CAs (Table 1). Furthermore, the two conservation areas with the lowest mean EAGB (ACAHN and ACCVC) also had the lowest mean density of large trees $\left(6.20 \pm 3.54\right.$ and $6.73 \pm 4.00$ tree ha $^{-1}$ respectively). Across all conservation areas, a pairwise 

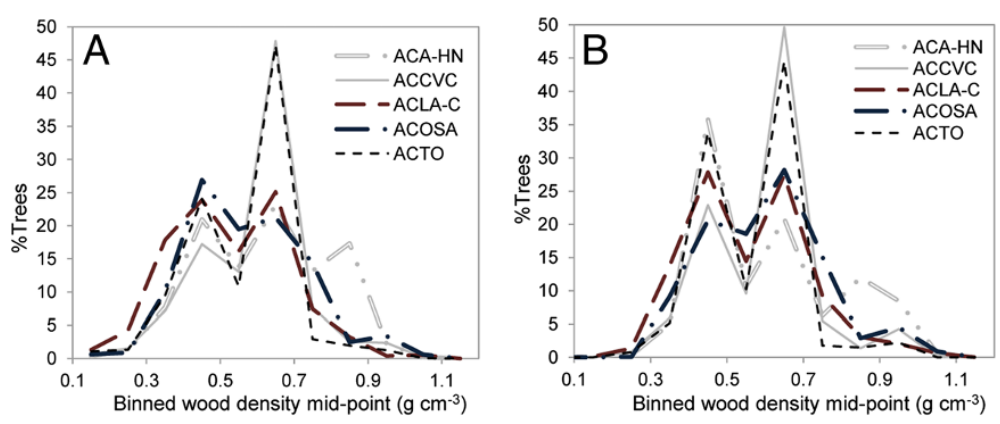

Figure 2 The distribution of wood density within five CAs. The percentage of trees that occupy consecutive $0.1 \mathrm{~g} \mathrm{~cm}^{-3}$ wood density bins in NFMP where $(\mathbf{A})$ inventories $(\mathrm{DBH} \geq 30 \mathrm{~cm})$ and $\mathbf{( B )}$ censuses $(\mathrm{DBH} \geq 60 \mathrm{~cm})$ in the five $C A$ s sampled.

$t$-test indicates a significantly higher number of large trees per hectare was recorded by the inventory than the census of the same forest stand $(\mathrm{n}=366, \mathrm{p}<0.01)$.

\section{Uncertainty analysis}

At the tree-level, when moving from species wood density $(\sigma \mathrm{M} \rho: \mathrm{sp}=0.110\langle\mathrm{EAGB}\rangle)$ to genus wood density $(\sigma \mathrm{M} \rho:$ gen $=0.151\langle\mathrm{EAGB}\rangle)$, we found a $4 \%$ increase in the uncertainty of EAGB due to wood density measurement error $(\sigma M \rho)$. We found that an even greater amount of EAGB uncertainty resulted from using NFMP $(\sigma \mathrm{M} \rho: \mathrm{NFMP}=0.271\langle\mathrm{EAGB}\rangle)$ or conservation area $(\sigma \mathrm{M} \rho: \mathrm{CA}=0.281$ 〈EAGB $\rangle)$ level wood density values. The uncertainty due to allometric model error $(\sigma \mathrm{A})$ for each tree was $0.371\langle$ EAGB〉. Hence, based on our Monte Carlo uncertainty analysis, the uncertainty of a tree's EAGB can range from $48 \%$ to $65 \%$ of its EAGB depending on the level of wood density used.

At the stand level, random measurement and allometric model errors counteract one another, decreasing their impact on EAGB uncertainty and increasing the overall precision of EAGB (Figure 7). The uncertainty of EAGB from a NFMP's inventory ranged from 0.021 $\langle E A G B\rangle$ to $0.171\langle E A G B\rangle$. At the census level, the uncertainty of EAGB for each NFMP ranged from 0.011 $\langle$ EAGB〉 to $0.101\langle$ EAGB $\rangle$.
We observed that the uncertainty of a given NFMP's EAGB was principally dependent on the number of trees sampled and the total area sampled (Figure 7). In Figure 7, we also observed that the uncertainty of EAGB decreases as the number of trees (Figure 7A) and the total area sampled increases (Figure 7B and $7 \mathrm{C}$ ) following a power function.

\section{Discussion}

\section{The variability of wood density}

Our study demonstrates for the first time the variability of wood density across five Costa Rican conservation areas based on pre-felling inventory data. We found the most northern forests included in our study, located in ACAHN, typically contain trees of higher wood density than those located in the other conservation areas sampled. In contrast, our results show that the southeastern lowland forests of ACLA-C house trees that tend to have lower wood density values. The regional differences between wood density values detected by our study indicate the importance of including this variable for the production of AGB estimates that are comparable at regional scales across Costa Rica. This variation also suggests that using more general country or pantropical scale wood density values when estimating AGB may lead to inaccurate results, underestimating the variability

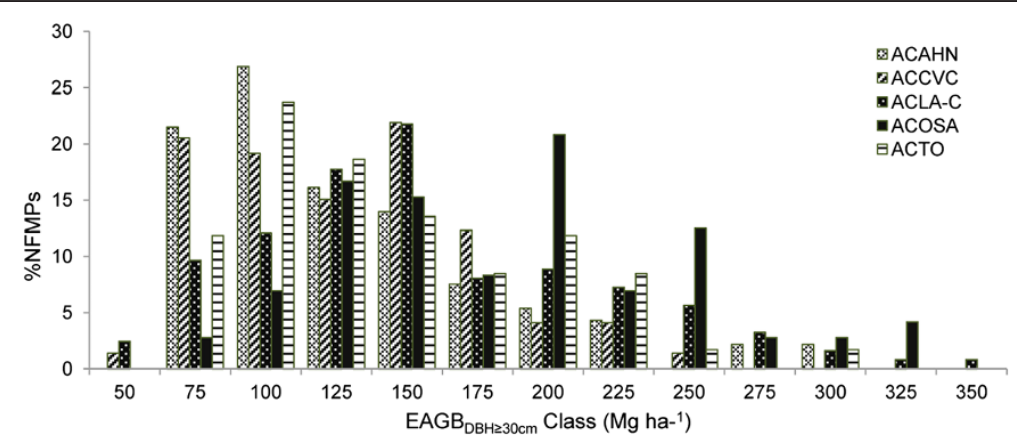

Figure 3 The distribution of inventory EAGB $\left(\mathrm{DBH} \geq \mathbf{3 0} \mathrm{cm}\right.$ ) per CA. The distribution is shown by the percentage of NFMPs within $25 \mathrm{Mg}^{-1}$ EAGB bins. 
Table 2 EAGB $\left(\mathrm{Mg} \mathrm{ha}^{-1}\right.$ ) and large tree density (tree ha ${ }^{-1}$ ) per conservation area and sampling protocol

\begin{tabular}{|c|c|c|c|c|c|}
\hline \multirow[b]{2}{*}{ CA } & \multicolumn{3}{|c|}{ Inventory (Mean \pm Std) } & \multicolumn{2}{|c|}{ Census (Mean \pm Std) } \\
\hline & $\begin{array}{l}E A G B_{D B H} \geq 30 \mathrm{~cm} \\
\left(\mathrm{Mg} \mathrm{ha}^{-1}\right)\end{array}$ & $\begin{array}{l}E A G B_{D B H \geq 60 \mathrm{~cm}} \\
\left(\mathrm{Mg} \mathrm{ha}^{-1}\right)\end{array}$ & $\begin{array}{l}\text { Lrg tree density } \\
\left(\text { tree } \mathrm{ha}^{-1} \text { ) }\right.\end{array}$ & $\begin{array}{l}\mathrm{EAGB}{ }_{\mathrm{DBH} \geq 60 \mathrm{~cm}} \\
\left(\mathrm{Mg} \mathrm{ha}^{-1}\right)\end{array}$ & $\begin{array}{l}\text { Lrg tree density } \\
\left(\text { tree } \mathrm{ha}^{-1} \text { ) }\right.\end{array}$ \\
\hline ACAHN & $118.07 \pm 54.09$ & $65.25 \pm 33.81$ & $6.29 \pm 3.55$ & $39.77 \pm 23.48$ & $4.25 \pm 2.72$ \\
\hline ACCVC & $116.17 \pm 44.48$ & $63.35 \pm 29.99$ & $6.71 \pm 4.02$ & $45.22 \pm 26.05$ & $5.27 \pm 3.39$ \\
\hline ACLA-C & $143.38 \pm 62.18$ & $79.83 \pm 48.29$ & $9.21 \pm 5.98$ & $53.60 \pm 27.89$ & $6.15 \pm 2.99$ \\
\hline ACOSA & $173.39 \pm 60.64$ & $123.27 \pm 53.56$ & $16.30 \pm 7.97$ & $58.35 \pm 23.24$ & $7.65 \pm 2.79$ \\
\hline ACTO & $130.30 \pm 51.05$ & $80.12 \pm 39.21$ & $10.70 \pm 6.26$ & $52.36 \pm 31.46$ & $6.98 \pm 4.27$ \\
\hline
\end{tabular}

of EAGB across tropical regions [28,29]. The regional wood density values found express the similarities and differences in species composition between the five conservation areas studied. Beyond species composition, it is also known that wood density is closely linked to a forest's functional composition as light-demanding fastgrowing species commonly have lower wood densities than shade-tolerant ones $[44,45]$. Building upon this idea, we believe that both natural and human disturbance regimes may play a key role in shaping the variation of EAGB and wood density among the forest stands and conservation areas studied.

\section{The variability of EAGB}

The variation of EAGB among NFMPs within any given conservation area reveals the heterogeneity of EAGB across the five conservation areas (Figure 1). We found, based on the pre-felling data, that the forest stands of ACOSA are some of the most biomass rich areas of Costa Rica while, those of ACAHN are some of the most biomass poor. Supporting the findings of Stegen et al. [46], a comparison of conservation area level wood density and EAGB trends suggests that wood density alone cannot explain regional EAGB variability. For example, despite having one of the highest mean wood density values, ACAHN has one of the lowest mean EAGB values. The variation of EAGB between NFMPs was very

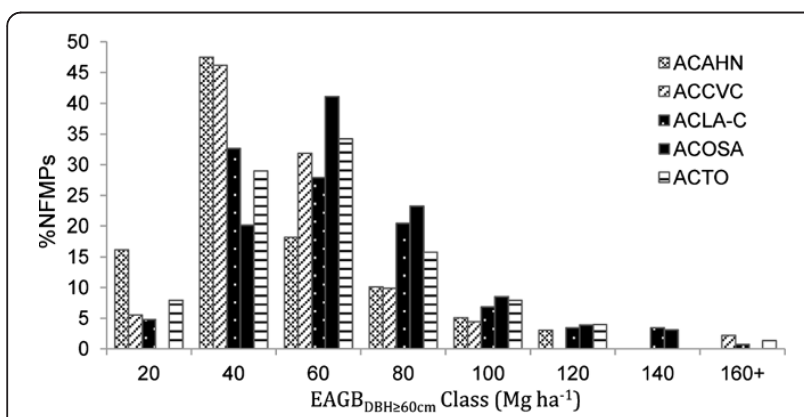

Figure 4 The distribution of census EAGB $(\mathrm{DBH} \geq 60 \mathrm{~cm})$ per CA. The distribution is shown by the percentage of NFMPs within $20 \mathrm{Mg}$ ha -1 EAGB bins. high, as indicated by the large standard deviation of EAGB among conservation areas (Table 2). Our findings highlight the need for a better understanding of both the environmental and human variables influencing the distribution of EAGB across spatial scales. For example, studies have found that forest fragmentation has a strong negative impact on AGB and AGC (aboveground carbon) due to a significant increase in the mortality of large trees near forest edges $[47,48]$. A greater comprehension of the factors controlling EAGB distribution will allow for the production of more reliable EAGB maps at local, regional, and national scales. Comparing the AGB estimates of our study to published estimates reveals that, in the regions of Costa Rica where EAGB has been previously sampled, our NFMP based approach produced a similar range of values. A study conducted at the La Gamba biological station in ACOSA reported the EAGB of trees with a $\mathrm{DBH} \geq 30 \mathrm{~cm}$ was $218.46 \pm$ $29.01 \mathrm{Mg} \mathrm{ha}^{-1}$ [49]. After considering one standard deviation from the mean, the EAGB determined from NFMPs $\left(173.47 \pm 60.23 \mathrm{Mg} \mathrm{ha}^{-1}\right)$ overlaps with the published estimates of Hofhansl et al. [49]. At ACCVC's La

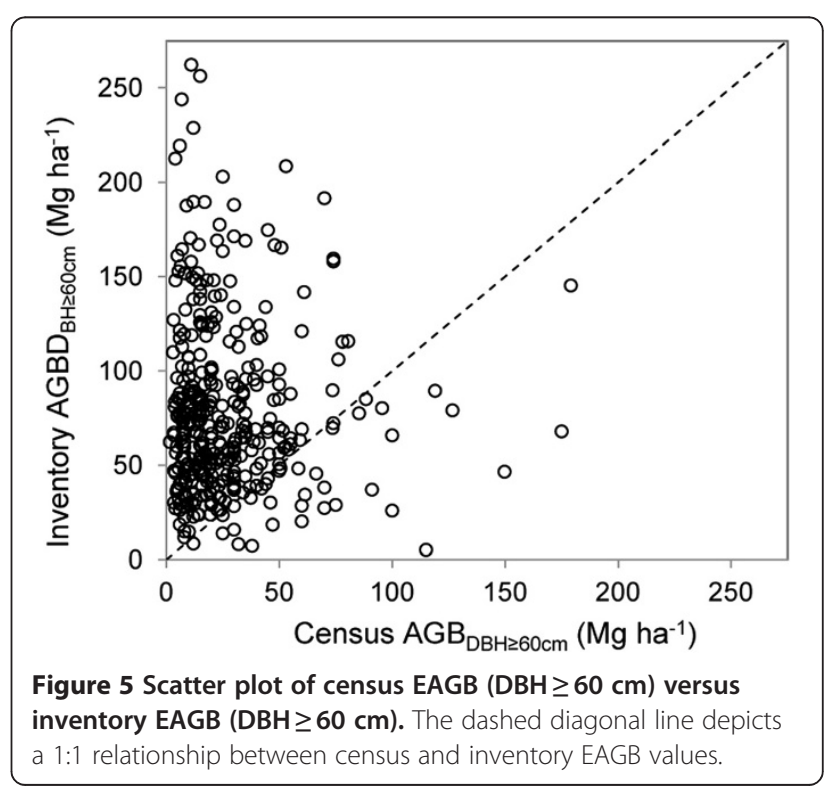



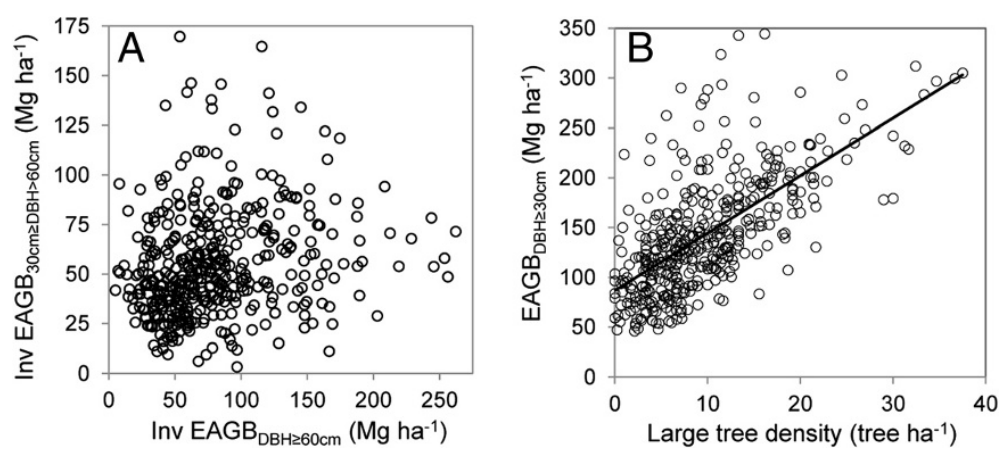

Figure 6 The relationship between the components of forest structure for trees of different sizes. (A) Scatter plot of inventory EAGB $(60 \mathrm{~cm}>\mathrm{DBH} \geq 30 \mathrm{~cm}$ ) versus inventory EAGB (DBH $\geq 60 \mathrm{~cm}$ ). The distribution of points within the scatter plot reveals the variation found between these two EAGB DBH classes; (B) The relationship between the density of large trees $(\mathrm{DBH} \geq 70 \mathrm{~cm})$ and $E A G B(D B H \geq 30 \mathrm{~cm})$. The line fit through the data explains $53.3 \%$ of the variation in EAGB.

Selva biological station, Clark and Clark [17] found the density of large trees ranged from 4.7 to 10.1 stems ha $^{-1}$ and the EAGB of large trees $(\mathrm{DBH} \geq 70 \mathrm{~cm})$ ranged from 22.6 to $55.4 \mathrm{Mg} \mathrm{ha}^{-1}$. The analysis of ACCVC NFMPs found values comparable to those reported by Clark and Clark [17], with a large tree density of $5.27 \pm 3.39$ tree ha $^{-1}$ (census) and $6.71 \pm 4.02$ tree $^{-1}$ (inventory) and a large tree $(\mathrm{DBH} \geq 70 \mathrm{~cm})$ EAGB of $27.53 \pm 18.06 \mathrm{Mg} \mathrm{ha}^{-1}$ (census) and $34.84 \pm 22.43 \mathrm{Mg} \mathrm{ha}^{-1}$ (inventory). This indicates a positive aspect in using NFMP data for assessing biomass and carbon [18].

Over half of the variation in EAGB across the five conservation areas sampled in this study was explained by the density of large trees. Although the strength of this predictive variable was approximately $20 \%$ less than the value reported by Slik et al. [32], our study supports the conclusion that large tree density accounts for a significant portion of EAGB variability across tropical regions. Additionally, we found that the patterns of EAGB and large tree density matched among conservation areas, demonstrating the importance of large trees as drivers of regional EAGB differences across Costa Rica.

Despite such a great amount of EAGB variability across NFMPs, a weak relationship was found between the EAGB of trees with a DBH $<60 \mathrm{~cm}$ but $\geq 30 \mathrm{~cm}$ and the EAGB of trees with a $\mathrm{DBH} \geq 60 \mathrm{~cm}$. If these results are consistent throughout other components of forest biomass, they indicate that models developed to estimate unmeasured portions of forest biomass based solely on the EAGB of measured forest components (e.g. [18]) may lead to an underestimation of the variability of forest biomass across the tropics. Future studies aiming to identify key variables that best explain how EAGB is distributed throughout different DBH classes and other forest stand components (e.g. lianas, coarse woody debris) could greatly improve the accuracy of AGB estimates (particularly in smaller trees) and in turn, the effort required to conduct large scale studies.
Our results show that the plot based sampling methodology of NFMPs (i.e. the inventory) tends to overestimate EAGB when compared to EAGB values calculated from the census of an entire forest stand. Houghton et al. [50] reported a similar result, finding a weak negative correlation between area sampled and EAGB. Both our results and those of Houghton et al. [50] indicate that the total area sampled may have important negative impacts on tropical AGB estimates. An additional source of the differences found may be explained by the location and distribution of inventory plots within forest stands. Although NFMP protocols specify that plots be randomly placed, we found a significant bias towards higher EAGB regions of the forest stand. As we do not have data to fully resolve the reason behind the bias, we hypothesize that it may be explained by a desire to achieve a higher economic outcome from the NFMP (i.e. to $\log$ a greater number of species and trees) and/or to reduce sampling effort (i.e. the placement of plots in more convenient areas of the forest stand). No matter the reason behind the bias, this finding brings to light the need to evaluate the sustainability of forest management practices in Costa Rica. If inventories are not only overestimating the number and EAGB of trees with a $\mathrm{DBH} \geq 60 \mathrm{~cm}$, but the number and EAGB of trees within the $30 \mathrm{~cm}$ to $60 \mathrm{~cm}$ DBH range, they may also be overestimating the capacity of forests to recover after a selective logging event [51].

\section{The uncertainty of EAGB}

Our uncertainty analysis explored how incorporating wood density values at different scales in allometric models will introduce different amounts of uncertainty into a tree's estimated AGB. We found that more general stand level and regional wood densities can lead to uncertainties in the EAGB of a single tree between 27\% and $28 \%$. Further, we investigated how much the uncertainty of a tree's EAGB will increase when using a genus 

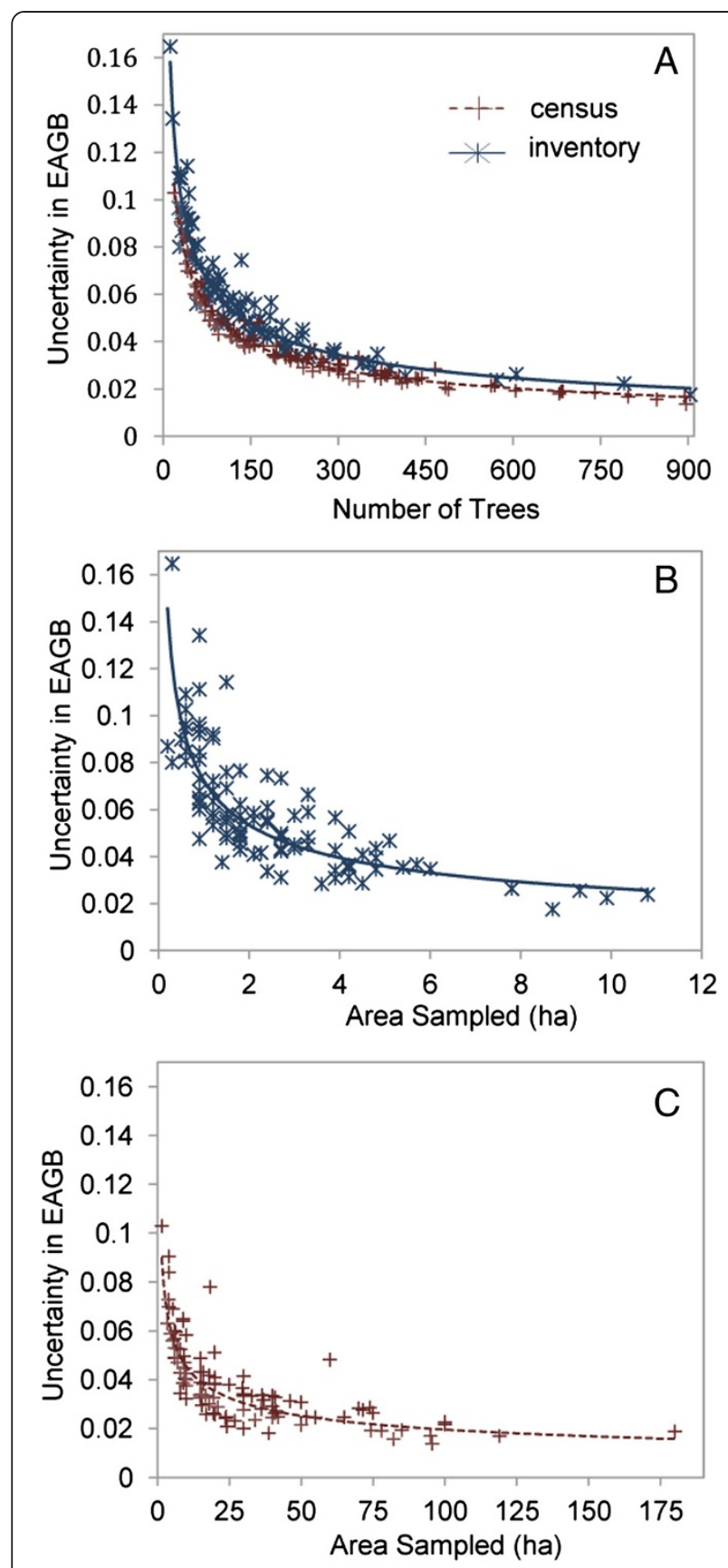

Figure 7 The relationship between the uncertainty in EAGB per NFMP and sampling effort. (A) The total number of trees sampled per NFMP; (B) the total area sampled per NFMP inventory; and (C) the total area sample per NFMP census. Uncertainty is given in unit-less value that varies from 0 to 1 . The solid (inventory) and dashed (census) lines depict the best fit function (power).

versus a species level wood density average. Although the $4 \%$ increase in uncertainty reflects the taxonomic composition of the forest stands sampled in this study, we believe that future work should consider this source of uncertainty when reporting EAGB estimates. Particularly, studies should pay greater attention to species and genera that exhibit high levels of wood density variability in the tropics (refer to Chave et al. [52] for a list of genera). The impact of wood density variability on EAGB uncertainty will be the greatest when (1) the species and/or genera sampled are highly variable and (2) the highly variable species and/or genera compose a notable portion of a forest stems and the wood density values incorporated into allometric models. When moving from the tree level to the plot level, the uncertainties introduced by measurement errors (wood density or DBH) decrease as the number of trees sampled increases. Errors introduced by the allometric model, on the other hand, can be either an issue of accuracy or precision $[18,33]$. If the allometric error is consistent, regardless of sample size, an accuracy error is present (i.e. the allometric model does not apply to or represent the given area). If the allometric error differs between trees and decreases with an increase in sample size, it is a precision error. As this study does not include direct tree biomass measurements collected via destructive sampling, the accuracy of the allometric model could not be addressed [10]. Therefore, in our uncertainty analysis we simulated the impact of random allometric model error on EAGB to evaluate the precision of the allometric models, finding that allometric model errors introduced $37 \%$ uncertainty to tree level EAGB values. It is important to note that the development of Chave et al.'s [25] wet forest model included samples collected in Costa Rica (La Selva) while the moist forest equation did not. Future studies should evaluate the accuracy and applicability of these models in Costa Rican forests, particularly those that did not incorporate any Costa Rican data during their development.

Allometric model selection is an important source of error that was not directly addressed in this study. Several studies comparing the results of allometric models have shown they produce vastly differing results (e.g. [33,53-55]). Further, Pelletier et al. [55] demonstrated that two different allometric models can result in estimated annual emissions from deforestation that differ by up to $48 \%$. Given the potential impact of model selection on forest biomass estimates and in turn, the success of international mechanisms such as REDD+, future studies will need to consider this source of uncertainty. In this study we consciously selected the Chave et al. [25] models as they fulfill several key criteria (the inclusion of wood density, representation of a large DBH range, and development from a large sample size).

Feldpausch et al. [56,57] found that an additional source of error in AGB estimates results from the exclusion of height as a predictor variable in allometric models. Regardless of this finding, Feldpausch et al. [57] also reported that the decrease in AGB estimation occurred only in smaller DBH classes $(\geq 40 \mathrm{~cm})$ and not 
larger ones. As our study only includes trees with a $\mathrm{DBH} \geq 30 \mathrm{~cm}$, we believe that the exclusion of height in the models applied to estimate AGB will not greatly increase the error of the reported values.

\section{Conclusions}

Our study presents the most spatially rich analysis of ground level EAGB data in Costa Rica to date. Using data from forest management inventories, we found that the EAGB within and among five Costa Rican conservation areas is highly variable. Further, we detected bias in the NFMPs towards biomass rich areas of the forest stand, demonstrating the need to assess the sustainability of Costa Rican forest management practices. Expanding upon this finding, if ecological plots are also being preferentially located in more easily accessible areas of forest stands, studies may not be accurately capturing the EAGB of tropical forests [10].

Despite the potential taxonomic issues and missing DBH classes within NFMPs, our EAGB values were comparable to those reported in the scientific literature, supporting their inclusion in future EAGB assessments. Currently, the ground level data used to produce largescale AGB and aboveground carbon maps is predominantly collected from ecological studies. Although this data is detailed and systematic in nature, ecological plots tend to sample either protected regions of the landscape or areas subject to a lesser amount of human impact. Forest management data, on the other hand, covers a considerable portion of the tropics and represents forests that are being greatly impacted by anthropogenic activities. In fact, Asner et al. [9] found that human activity was the greatest driver of AGB and aboveground carbon in the forests of Panama, highlighting the need measure the impact of humans on the variability of AGB and AGC across the tropics. Combining commercial logging inventories with ecological plots will provide a more representative ground level dataset for the calibration of the models and remotely sensed data used to estimate AGB and aboveground carbon at regional and national scales. Additionally, it is the non-protected areas of the tropics that offer the greatest opportunity to reduce rates of deforestation and forest degradation. Therefore, by improving our knowledge on the variability of aboveground carbon and AGB through forest management data, studies can better support the REDD + mechanism and the sustainable management of the rich natural resources of the tropics.

\section{Competing interests}

The authors declare that they have no competing interests.

\section{Authors' contributions}

SS carried out the data analysis and wrote the manuscript. JPA-M helped in the design of the study and together with MK reviewed the manuscript and provided valuable comments for the its overall improvement. All authors read and approved the final manuscript.

\section{Acknowledgements}

We would like to thank Lic. Maria Isabel Chavarria from the Costa Rican Forestry Resources Information System (SIREFOR) office and Mr. Gilbert Canet from the National System of Conservation Areas (SINAC) for providing support and access to the forest management plan hard copies during previous stages of this project. Special thanks to Professor Catherine Potvin at McGill University for revising the manuscript and providing valuable comments. Additional thanks to the two anonymous reviewer s comments. Funding was provided by the Global Environment and Climate Change Center at McGill University (to Arroyo-Mora), the Department of Geography, the Natural Sciences and Engineering Research Council Canada, the Canada Foundation for Innovation (to Kalacska), the ESRI inc. McGill Undergraduate GIS award, and the Rathlyn GIS Award (to Svob).

Received: 12 December 2013 Accepted: 8 September 2014

Published online: 17 September 2014

\section{References}

1. Bradshaw CJA, Sodhi NS, Brook BW: Tropical turmoil: a biodiversity tragedy in progress. Front Ecol Environ 2009, 7(2):79-87.

2. Pan Y, Birdsey RA, Fang J, Houghton R, Kauppi PE, Kurz WA, Phillips OL, Shvidenko A, Lewis SL, Canadell JG, Ciais P, Jackson RB, Pacala SW, McGuire $A D$, Piao S, Rautiainen A, Sitch S, Hayes DA: Large and persistent carbon sink in the world's forests. Science 2011, 333:988-993.

3. Saatchi SS, Harris NL, Brown S, Lefsky M, Mitchard ETA, Salas W, Zutta BR, Buermann W, Lewis SL, Hagen S, Petrova S, White L, Silman M, Morel A: Benchmark map of forest carbon stocks in tropical regions across three continents. Proc Natl Acad Sci 2011, 108:9899-9904.

4. Baccini A, Goetz SJ, Walker WS, Laporte NT, Sun M, Sulla-Menashe D, Hackler J, Beck PSA, Dubayah R, Friedl MA, Samanta S, Houghton RA: Estimating carbon dioxide emissions from tropical deforestation improved by carbon-density maps. Nat Clim Change 2012, 2:182-185.

5. Malhi Y, Grace J: Tropical forests and atmospheric carbon dioxide. TREE 2000, 15(8):332-337.

6. Van de Werf GR, Morton DC, DeFries RS, Oliver JGJ, Kasibhatla PS, Jackson $\mathrm{RB}$, Collatz GJ, Randerson JT: $\mathrm{CO}_{2}$ emissions from forest loss. Nat Geosci 2009, 2:737-738.

7. Gibbs HK, Brown S, Niles JO, Foley JA: Monitoring and estimating tropical forest carbon stocks: making REDD a reality. Environ Res Lett 2007, 2:1-13.

8. Petrokofsky G, Homgren P, Brown ND: Reliable forest carbon monitoring systematic reviews as a tool for validating the knowledge base. Int For Rev 2011, 13(1):56-66.

9. Asner GP, Mascaro J, Anderson C, Knapp DE, Martin RE, Kennedy-Bowdoin T, van Breugel M, Davies S, Hall JS, Muller-Landau HC, Potvin C, Sousa W, Wright J, Bermingham E: High-fidelity national carbon mapping for resource management and REDD+. Carbon Bal Manag 2013, 8:7.

10. Clark DB, Kellner J: Tropical forest biomass estimation and the fallacy of misplaced concreteness. J Vegetation Sci 2012, 23:1191-1196.

11. Mitchard ETA, Saatchi SS, Baccini A, Asner GP, Goetz SJ, Harris NL, Brown S: Uncertainty in the spatial distribution of tropical forest biomass: a comparison of pan-tropical maps. Carbon Bal Manag 2013, 8:10.

12. Hill TH, William M, Bloom AA, Mitchard ETA, Ryan CM: Are inventory based and remotely sensed above-ground biomass estimates consistent? PLOS One 2013, 8(9):e74170. doi:10.1371/journal.pone.0074170.

13. Drake JB, Dubayah RO, Knox RG, Clark DB, Blair JB: Sensitivity of largefootprint lidar to canopy structure and biomass in neotropical rainforest. Remote Sens Environ 2002, 81(2-3):378-392.

14. Patenaude GR, Milne R, Dawson TP: Synthesis of remote sensing approached for forest carbon estimation: reporting on the Kyoto Protocol. Environ Sci Pol 2005, 8(2):161-178.

15. Goetz SJ, Baccini A, Laporte NT, Johns T, Walker W, Kellndorfer J, Houghton RA, Sun M: Mapping and monitoring carbon stocks with satellite observations: a comparison of methods. Carbon Balance Manag 2009, 4:2.

16. Brown S, Lugo AE: Aboveground biomass estimates for tropical moist forests of the Brazilian Amazon. Interciencia 1992, 17(1):8-18

17. Clark DB, Clark DA: Landscape-scale variation in forest structure and biomass in a tropical rain forest. For Ecol Manage 2000, 137:185-198.

18. Maniatis D, Malhi Y, André LS, Mollicone D, Barbier N, Saatchi S, Henry M, Tellier L, Schwartzenberg M, White L: Evaluation the potential of commercial forest inventory data to report on forest carbon stock and 
forest carbon stock changes for REDD + under the UNFCCC. Int J Forest Res 2011, 2001:1-14.

19. Couteron P, Pélissier R, Mapaga D, Molino JF, Tellier L: Drawing ecological insights from a management-oriented forest inventory in French Guiana. For Ecol Manage 2003, 172:89-108.

20. Putz RE, Blate GM, Redford KH, Fimbel R, Robinson J: Tropical forest management and conservation of biodiversity: an overview. Conserv Biol 2001, 15:7-20

21. Réjou-Méchain M, Fayolle A, Nasi R, Gourlet-Fleury S, Doucet J-L, Gally M, Hubert D, Pasquier A, Billand A: Detecting large-scale diversity patterns in tropical trees: can we trust commercial forest inventories? For Ecol Manage 2011, 261:187-194.

22. Arroyo-Mora JP, Chazdon RL, Kalacska M, Obando G, Aguilar L, Salas LF: Development of a forest management GIS for Costa Rica, a case study for the Central Volcanic Cordillera conservation area: management trends, lessons and potential uses in ecological research and conservation planning. In Proceedings of the XXIII World Forestry Congress. Buenos Aires, Argentina: 2009.

23. Boza MA: Conservation in action: past, present, and future of the national park system of Costa Rica. Conserv Biol 1993, 7(2):239-247.

24. Svob S, Arroyo-Mora JP, Kalacska M: The development of a forestry geodatabase for natural forest management plans in Costa Rica. For Ecol Manage 2014, 327:240-250

25. Chave J, Andalo C, Brown S, Cairns MA, Chamber JQ, Eamus D, Fölster H, Fromard F, Higuchi N, Kira T, Lescure J-P, Nelson BW, Ogawa H, Puig H, Riéra B, Yamakura T: Tree allometry and improved estimation of carbon stocks and balance in tropical forests. Oecologia 2005, 145:87-99.

26. Keeling HC, Phillips OL: The global relationship between forest productivity and biomass. Glob Ecol Biogeogr 2007, 16:618-631

27. Baker TR, Phillips OL, Laurance WF, Pitman NCA, Almeida S, Arroyo L, DiFiore A, Erwin T, Higuchi N, Killen TJ, Laurance SG, Nascimento H, Monteagudo A, Neil DA, Silva JNM, Malhi Y, Gonzalez GL, Peacock J, Quesada CA, Lewis SL, Lloyd J: Do species traits determine patterns of wood production in Amazonian forests? Biogeosciences 2009, 6:297-307.

28. Baker TR, Philips OL, Malhi Y, Almeidas S, Arroyo L, Di Fiore A, Erwin T, Killeen TJ, Laurance SG, Laurance WF, Lewis SL, Lloyd J, Monteagudos A, Neill DA, Patiño S, Pitman NCA, Silva JNM, Martínez RV: Variation in wood density determines spatial patterns in Amazonian forest biomass. Glob Chang Biol 2004, 10:545-562.

29. Muller-Landau HC: Interspecific and inter-site variation in wood specific gravity of tropical trees. Biotropica 2004, 36(1):20-32

30. Chave J, Coomes D, Jansen S, Lewis SL, Swenson NG, Zane AE: Towards a worldwide wood economics spectrum. Ecol Lett 2009, 12:351-366.

31. Zhang S-B, Slik JWF, Zhang J-L, Cao K-F: Spatial patterns of wood traits in China are controlled by phylogeny and the environment. Glob Ecol Biogeogr 2011, 20:241-250.

32. Slik JW, Paoli G, McGuire K, Amaral I, Barroso J, Bastian M, Blanc L, Bongers F, Boundja P, Clark C, Collins M, Dauby G, Ding Y, Doucet J-L, Eler E, Ferreira L, Forshed O, Fredriksson G, Gillet J-F, Harris D, Leal M, Laumonier Y, Malhi Y, Mansor A, Martin E, Miyamoto K, Araujo- Murakami A, Nagamasu H, Nilus R, Nurtiahya $\mathrm{E}$, et al: Large trees drive forest aboveground biomass variation in moist lowland forests across the tropics. Glob Ecol Biogeogr 2013, 22(12):1261-1271.

33. Chave J, Chust G, Condit R, Aguilar S, Hernandez A, Lao S, Perez R: Error Propagation and Scaling for Tropical Forest Biomass Estimates. In Tropical Forests and Global Atmospheric Change. Edited by Malhi Y, Philips O. London: Oxford University Press; 2009:155-166.

34. Brown S: Estimating Biomass and Biomass Change of Tropical Forests: A Primer. FAO Rome: UN FAO Forestry Paper 134; 1997:55.

35. Letcher SG, Chazdon RL: Rapid recovery of biomass, species richness, and species composition in a forest chronosequence in Northeastern Costa Rica. Biotropica 2009, 41(5):608-617.

36. Clark ML, Roberts DA, Ewel JJ, Clark DB: Estimation of tropical rain forest aboveground biomass with small-footprint lidar and hyperspectral sensors. Remote Sens Environ 2011, 115(11):2931-2942.

37. Zanne AE, Lopez-Gonzalez G, Coomes DA, llic J, Jansen S, Lewis SL, Miller RB, Swenson NG, Wiemann MC, Chave J: Data from: towards a worldwide wood economics spectrum. Dryad Digital Repository 2009, doi:10.5061/ dryad.234

38. Williamson GB, Wiemann MC: Age-dependent increases in wood specific gravity of tropical pioneers in Costa Rica. Biotropica 2010, 42(5):590-597.
39. Arroyo-Mora JP, Svob S, Kalacska M: Historical patterns of natural forest management in Costa Rica: the good, the bad and the ugly. Forests 2014, 5(7):1777-1797.

40. Holdridge LR: Life Zone Ecology. San Jose, Costa Rica: IICA Press; 1979.

41. Instituto Tecnológico de Costa Rica: Atlas Costa Rica 2008. Cartago, Costa Rica: 2008:1 CD.

42. Rangel TFLVB, Diniz-Filho JAF, Bini LM: Towards an integrated computational tool for spatial analysis in macroecology and biogeography. Glob Ecol Biogeogr 2006, 15:321-327.

43. Lacerda AEB, Nimmo ER: Can we really manage tropical forests without knowing the species within? Getting back to the basics of forest management through taxonomy. For Ecol Manage 2010, 259:995-1002.

44. King DA: Correlations between biomass allocation, relative growth rate and light environment in tropical forest saplings. Funct Ecol 1991, 5(4):485-492.

45. Whitmore TC: An Introduction to Tropical Rain Forests. Oxford: Oxford University Press; 1998.

46. Stegen JC, Swenson NG, Valencia R, Enquist BJ, Thompson J: Aboveground forest biomass is not consistently related to wood density in tropical forests. Glob Ecol Biogeogr 2009, 18:617-625.

47. Laurance WF, Delamônica R, Laurance SG, Vasconcelos HL, Lovejoy TE: Rainforest fragmentation kills big trees. Nature 2000, 404:836.

48. Nasciemento HEM, Laurance WF: Biomass dynamics in Amazon forest fragments. Ecol Appl 2004, 14((4) supplement):S127-S138

49. Hofhansl F, Wanek W, Drage S, Huber W, Weissenhofer A, Richter A: Controls of hydrochemical fluxes via stemflow in tropical lowland rainforests: effects of meteorology and vegetation characteristics. J Hydrol 2012, 452-453:247-258.

50. Houghton RA, Lawrence KT, Hackler JL, Brown S: The spatial distribution of forest biomass in the Brazilian Amazon: a comparison of estimates. Glob Chang Biol 2001, 7:731-746.

51. Blanc L, Echard M, Herault B, Bonal D, Marcon E, Chave J, Baraloto C: Dynamics of aboveground carbon stocks in a selectively logged tropical forest. Ecol App/ 2009, 19(6):1397-1404.

52. Chave J, Muller-Landau HC, Baker TR, Easdale TA, Ter Steege H, Webb CO: Regional and phylogenetic variation of wood density across 2456 neotropical tree species. Ecol Appl 2006, 16(6):2356-2367.

53. Segura M, Kanninen M: Allometric models for tree volume and total aboveground biomass in a humid tropical forest in Costa Rica. Biotropica 2005, 37(1):2-8.

54. Komiyama A, Eong Ong J, Poungparn S: Allometry, biomass, and productivity of mangrove forests: a review. Aquatic Botany 2008, 89(2):128-137.

55. Pelletier J, Kirby R, Povin C: Significance of carbon stock uncertainties on emission reductions from deforestation and forest degadation in developing countries. Forest Pol Econ 2012, 24:3-11.

56. Feldpausch TR, Banin L, Phillips OL, Baker TR, Lewis SL, Quesada CA, AffumBaffoe K, Arets EJMM, Berry NJ, Bird M, Brondizio ES, de Camardo P, Chave J, Djagbletey G, Domingues TF, Drescher M, Fearnside PM, França MB, Fyllas NM, Lopez-Gonzalez G, Hladik A, Higuchi N, Hunter MO, lida Y, Salim KA, Kassim AR, Keller M, Kemp J, King DA, Lovet JC, et al: Height-diameter allometry of tropical forest trees. Biogeosciences 2011, 8:1081-1106.

57. Feldpausch TR, Lloyd J, Lewis SL, Brienen RJW, Gloor M, Monteagudo Mendoza A, Lopez-Gonzalez G, Banin L, Abu Salim K, Affum-Baffoe K, Alexiades M, Almeida S, Amaral I, Andrade A, Aragão LEOC, Araujo Murakami A, Arets EMMM, Arroyo L, Aymard CGA, Baker TR, Bánki OS, Berry NJ, Cardozo N, Chave J, Comiskey JA, Alvarez E, de Oliveira A, Di Fiore A, Djagbletey G, Domingues TF, et al: Tree height integrated into pantropical forest biomass estimates. Biogeosciences 2012, 9:3381-3403.

doi:10.1186/s13021-014-0009-y

Cite this article as: Svob et al:: A wood density and aboveground biomass variability assessment using pre-felling inventory data in Costa Rica. Carbon Balance and Management 2014 9:9. 